\title{
Higher serum IL-17A along with anti-tTG antibodies for prediction of refractory celiac disease
}

\author{
Tsvetelina V Velikova ${ }^{1 *}$, Zoya A Spassova ${ }^{2}$, Kalina D Tumangelova-Yuzeir ${ }^{3}$, Ekaterina K \\ Krasimirova ${ }^{3}$, Ekaterina I Ivanova-Todorova ${ }^{3}$, Dobroslav $\mathbf{S}$ Kyurkchiev ${ }^{3}$, Iskra $\mathbf{P}$ \\ Altankova 1
}

1 Clinical Immunology, University Hospital "Lozenetz," Sofia 2 Clinic of Gastroenterology, University Hospital "St. Ivan Rilski" Medical University, Sofia 3 Laboratory of Clinical Immunology, University Hospital "St. Ivan Rilski”, Department of clinical laboratory and clinical immunology, Medical University, Sofia

\begin{abstract}
Background: The role of IL-17A in celiac disease and refractory celiac disease remains elusive.

Aim: In this pilot study, we aimed to follow-up serologically (autoantibodies and IL-17A levels) twelve celiac disease patients on a gluten-free diet.
\end{abstract}

Methods: Twelve patients with histologically proven celiac disease were tested for anti-tissue transglutaminase (anti-tTG), anti-deamidated gliadin peptides (anti-DGP), and IL-17A at diagnosis and then adhered to the gluten-free diet for six months and tested again for the presence of autoantibodies.

Results: Three out of the twelve patients have shown high levels of serum IL-17A (average 103.2 \pm 24.5 $\mathrm{pg} / \mathrm{ml}$ ), and nine patients had IL-17A below the detection limit of the kit. At baseline, all patients showed positive results for celiac-related autoantibodies. The baseline level of cytokine IL-17A was higher in patients with no decrease of anti-tTG antibodies and persistent symptoms after six months of gluten-free diet compared to patients with decreased antibodies after gluten-free diet. The levels of anti-DGP decreased after gluten-free diet independently of the initial concentration of IL-17A.

Conclusions: By the obtained results, we could suggest that IL-17A may be involved in refractory celiac disease and initially higher IL-17 along with positive anti-tTG could be used as a prognostic factor for gluten-free diet response in these patients.

Citation: Velikova TV, Spassova ZA, Tumangelova-Yuzeir KD, Krasimirova EK, Ivanova-Todorova EI, Kyurkchiev DS, Altankova IS (2019) Higher serum IL-17A along with anti-tTG antibodies for prediction of refractory celiac disease, GJBAHS 8: 9 .

Received: January 24, 2019; Accepted: February 20, 2019; Published: February 27, 2019

Copyright: (C2019 Velikovaa TV, et al. This is an open-access article distributed under the terms of the Creative Commons Attribution License, which permits unrestricted use, distribution, and reproduction in any medium, provided the original author and source are credited.

Competing interests: The authors have declared that no competing interests exist.

Sources of funding: No funding.

*Email: tsvelikova@medfac.mu-sofia.bg

\section{Keywords:}

Celiac disease, Refractory celiac disease, Anti-ttg, IL-17A, Gluten-free diet

\section{Introduction}

Celiac disease (CD) is an autoimmune illness that develops in susceptible individuals exposed to gluten with a prevalence of about $1 \%$ of the general population worldwide [1]. The refractory $\mathrm{CD}$, a condition with persistent duodenal atrophy and malabsorption despite the strict adherence to gluten-free diet (GFD) and with other causes of villous atrophy excluded, can bring up to $50 \%$ mortality rate of the patients [1]. The role of IL-17A in the CD pathogenesis remains elusive although a few studies pointed out the cytokine implementation in the persistent inflammation, including in refractory $\mathrm{CD}$ [2]. It is well-known that Th17 cells have an essential role in numerous 
autoimmune diseases. Recent studies also showed that these cells are involved in CD pathogenesis, evidenced by using real-time qRT-PCR displaying amplified expression of Th17-related cytokines in patients with active $\mathrm{CD}$ compared to the normal group [2].

In this pilot study, we aimed to follow-up serologically (autoantibodies and IL-17A levels) twelve CD patients on GFD for a 12-month-period.

\section{Materials and Methods}

\section{Patients}

Twelve patients with histologically proven celiac disease at mean age $38 \pm 4$ years, eleven women, and one man were recruited to the study. Patients were tested for auto-antibodies and IL-17A at diagnosis and then adhered to the gluten-free diet (GFD) for six months and tested again for the presence of autoantibodies. All patients signed written informed consent, and the study was approved by the Ethics Committee of the Medical University of Sofia.

\section{Methods}

We tested serum samples of the patients for IL-17A (Human IL-17A ELISA kit, Diaclone, GenProbe, France), anti-tissue transglutaminase (anti-tTG) antibodies (Anti-Tissue Transglutaminase Screen IgA+IgG, Orgentec Diagnostika $\mathrm{GmbH}$ ) and antideamidated gliadin peptides (anti-DGP) antibodies (Quanta Lite Celiac DGP Screen IgA+IgG, Innova Diagnostics, Inc., San Diego, USA) at baseline, and then for anti-tTG and anti-DGP after 12 months on GFD.

\section{Results}

Three out of the twelve patients have shown high levels of serum IL-17A (average $103.2 \pm 24.5 \mathrm{pg} /$ $\mathrm{ml}$ ), and nine patients had IL-17A below the detection limit of the kit. At baseline all patients showed positive results for CD-related autoantibodies: anti-tTG (average 181.28 - above $200 \mathrm{U} / \mathrm{ml}$ ) and anti-DGP (average $150.33-169.57$ $\mathrm{U} / \mathrm{ml}$ ) (Table 1).

Table 1: Serum levels of anti-tTG and anti-DGP autoantibodies of celiac disease patients at baseline and after six months of gluten-free diet.

\begin{tabular}{llll}
\hline & & Baseline & \multicolumn{1}{c}{$\begin{array}{c}\text { After six months on a gluten- } \\
\text { free diet }\end{array}$} \\
\hline Patients with high level of IL-17A, & Anti-tTG, IU/ml & $>200,00$ & $>200,00$ \\
\hline $\mathrm{n}=3$ & Anti-DGP, IU/ml & 169.57 & 61.65 \\
\hline Patients with low level of IL-17A, $\mathrm{n}=9$ & Anti-tTG, IU/ml & 181.28 & 113.35 \\
\hline & Anti-DGP, IU/ml & 150.33 & 95.53 \\
\hline
\end{tabular}

We also found that the baseline level of cytokine IL-17A was higher in patients with no decrease of anti-tTG antibodies after at least six months of GFD compared to patients with decreased antibodies after GFD (Figure 1). These patients also complained of the persistent $\mathrm{CD}$ symptoms. The level of anti-tTG in patients with no IL-17A at baseline decreased after GFD. The levels of antiDGP decreased after GFD independently of the initial concentration of IL-17A (Table 1).

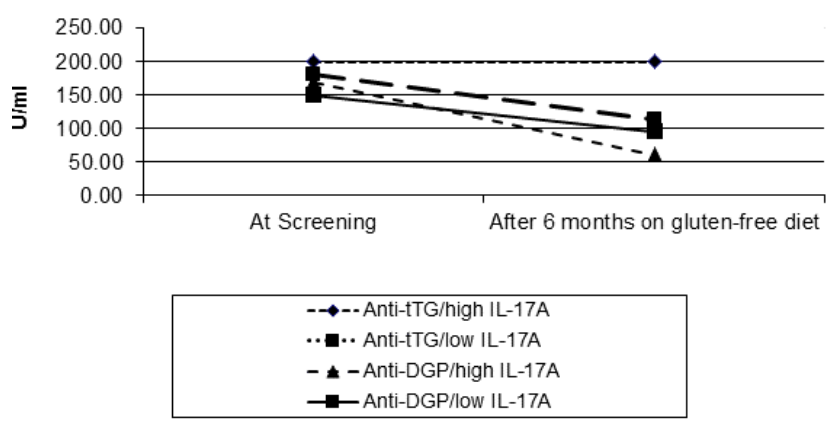

Figure 1: Trends of serum autoantibodies anti-tTG and antiDGP in celiac disease patients at baseline and after six months of gluten-free diet depending on the initial IL-17A level. 


\section{Discussion}

We observed that patients with initially higher serum IL-17A along with positive anti-tTG antibodies remained with high autoantibodies levels and persistent symptoms. We could speculate that IL-17A could have a role in the pathogenesis of refractory $\mathrm{CD}$. In line with this are the results from a study revealed upregulated IL-17A mRNA levels in both active $\mathrm{CD}$ and refractory $\mathrm{CD}$ [3]. Other studies presented evidence for the ability of gliadinspecific cells to produce IL-17A $[4,5]$. Contrasting results on the topic require further investigations.

In line with this, Bood et al. demonstrated that the primary source of IL-17 secretion is not gliadinspecific CD4+T cells but gluten-specific IL-17Aproducing cells [6]. The latter was in the duodenum of $\mathrm{CD}$ patients where they produce substantial amounts of IL-22. It was further confirmed that both IL-17 and IL-21 take part in mucosal immunity, thus, may exert a role in $\mathrm{CD}$ pathogenesis as well. Moreover, it was showed that gliadin-specific Th17 cells could also secrete the pro-inflammatory cytokines IFN- $\gamma$ and IL-21, the mucosal protective cytokine IL-22, and TGF- $\beta$. This evidence advocates for the plasticity of Th17 cells in autoimmunity and CD by secreting both pro-inflammatory and anti-inflammatory-cytokines. Th17 cells could also differentiate in $\mathrm{T}$ regulatory cells, and vice versa.

However, in our study, no one of the patients decreased the level of autoantibodies below the cut off of the tests $(10 \mathrm{U} / \mathrm{ml})$, which shows the need for more length of the diet. Nevertheless, all patients with high IL-17A remained with the levels of antitTG above the upper limit of detection. We are not certain whether the anti-tTG levels have decreased because they remained above the upper limit $(>200$ $\mathrm{U} / \mathrm{ml}$ ). The other limitation of this pilot study is the relatively small size of the study group. Advanced studies are required to support the hypothesis of IL-17A implementation in the refractory CD.
However, evidence suggested the role of Th17 in immune pathogenesis of $\mathrm{CD}$ and indicated the plasticity function. Thus, the role of mucosal cytokines related to Th17 cells is highlighted, especially of IL-17. As a new approach could be suggested anti-cytokine therapy approaches that target pro-inflammatory cytokines, could provide a promising and effective treatment for patients with CD.

\section{Conclusion}

The role of IL-17A in CD pathogenesis is still debated and open to investigation, but we could suggest that IL-17A may be involved in refractory CD. Our results showed that initially higher IL-17 along with positive anti-tTG stay stable in time and should be investigated further as a prognostic factor for patients with refractory celiac disease.

\section{References}

1. Shannahan S, Leffler DA. Diagnosis and updates in celiac disease. Gastrointest Endosc Clin N Am 2017;27(1): 79-92.

2. Monteleone I, Sarra M, Blanco DVG, Paoluzi OA, Franzè $\mathrm{E}$, et al. Characterization of IL-17A-producing cells in celiac disease mucosa. J Immunol 2010;184(4): 2211-2218.

3. Di Cagno R, De Angelis M, De Pasquale I, Ndagijimana $\mathrm{M}$, Vernocchi P, et al. Duodenal and faecal microbiota of celiac children: molecular, phenotype and metabolome characterization. BMC Microbiol 2011;11:219.

4. Mazzarella G. Effector and suppressor $\mathrm{T}$ cells in celiac disease World. J Gastroenterol 2015; 21(24):7349-7356.

5. Hisamatsu T, Erben U, Kühl AA. The Role of T-cell subsets in chronic inflammation in celiac disease and inflammatory bowel disease patients: more common mechanisms or more differences? Inflamm Intest Dis 2016;1:52

6. Faghih M, Barartabar Z, Nasiri Z. The role of Th1 and Th17 in the pathogenesis of celiac disease. Gastroenterol Hepatol Open Access 2018;9(2):83-87. 